Article

\title{
Comparison of Three Computational Approaches for Tree Crop Irrigation Decision Support
}

\author{
Panagiotis Christias ${ }^{1, *}$, Ioannis N. Daliakopoulos $2,3{ }^{-}$, Thrassyvoulos Manios ${ }^{2}$ and \\ Mariana Mocanu ${ }^{1}$ \\ 1 Faculty of Automatic Control and Computers, University Politehnica of Bucharest, 060042 Bucharest, \\ Romania; mariana.mocanu@cs.pub.ro \\ 2 Department of Agriculture, Hellenic Mediterranean University, 71410 Heraklion, Greece; \\ idaliak@hmu.gr (I.N.D.); tmanios@hmu.gr (T.M.) \\ 3 LANDCO S.A., 15122 Maroussi, Greece \\ * Correspondence: panagiotis.christias@cti.pub.ro
}

Received: 30 March 2020; Accepted: 15 April 2020; Published: 3 May 2020

check for updates

\begin{abstract}
This paper explores methodologies for developing intelligent automated decision systems for complex processes that contain uncertainties, thus requiring computational intelligence. Irrigation decision support systems (IDSS) promise to increase water efficiency while sustaining crop yields. Here, we explored methodologies for developing intelligent IDSS that exploit statistical, measured, and simulated data. A simple and a fuzzy multicriteria approach as well as a Decision Tree based system were analyzed. The methodologies were applied in a sample of olive tree farms of Heraklion in the island of Crete, Greece, where water resources are scarce and crop management is generally empirical. The objective is to support decision for optimal financial profit through high yield while conserving water resources through optimal irrigation schemes under various (or uncertain) intrinsic and extrinsic conditions. Crop irrigation requirements are modelled using the FAO-56 equation. The results demonstrate that the decision support based on probabilistic and fuzzy approaches point to strategies with low amounts and careful distributed water irrigation strategies. The decision tree shows that decision can be optimized by examining coexisting factors. We conclude that irrigation-based decisions can be highly assisted by methods such as decision trees given the right choice of attributes while keeping focus on the financial balance between cost and revenue.
\end{abstract}

Keywords: DSS; multicriteria; fuzzy logic; decision trees; ID3; irrigation management; olive trees

\section{Introduction}

Globally, the agricultural sector consumes the large majority (70\%) of water abstractions [1], nevertheless, the resulting water productivity ranges widely even for similar climates, locations and crops [2]. This extensive variability in crop water productivity under otherwise similar conditions, indicates that well planned agricultural management strategies [3,4] can improve sub-optimal yields. In the face of increasing demand [5] and climate change, both at the global [6] and the local scale [7], pressure on agricultural systems is expected to increase, and water scarcity will become a major limitation for sustainable development, especially in semi-arid regions [8].

Since their advent [9], irrigation decision support systems (IDSS) aim to facilitate "smart" water use that allows water users to decouple water consumption from yields, thus achieving economic growth with a lower environmental footprint [10]. Traditionally, these systems produce irrigation schedules based on deterministic models such as AquaCrop [11-13] or IRRINET [14] that eventually rely on the Food and Agriculture Organization (FAO) of the United Nations FAO-56 method [15] to estimate crop yield response to temperature and water availability. Despite the fact that numerous 
IDSS have been developed in the last decades [16], there is little evidence of widespread adoption [8]. This is because IDSS advice is of limited value or perhaps entirely irrelevant, as the underlying decision rules (water balances, financial models) are narrower in scope than the actual criteria farmers use to make decisions with [17] or require more certain data.

Probabilistic methods have mainly been used to support decision systems implementation [18]. Fuzzy sets theory provide tooling to represent mathematical uncertainties [19] despite the fact that the probability theory has been mainly used for this purpose. All random processes can be represented by probabilities. Nevertheless, not all uncertain events are also random. Fuzzy sets help to model the uncertainty associated with ambiguity, inaccuracy and lack of information in a decision problem [18]. Ultimately, we aim to integrate the intuition we have into a problem's solution. The key characteristic of fuzzy logic is the use of qualitative (linguistic) variables instead of quantitative variables to represent inaccuracy. Fuzzy methods power decision intelligence in economics [20], medical diagnosis [21,22] and engineering [23,24]. The use of fuzzy logic in solving a decision problem involves a degree of tolerance in the inaccuracy to characterize data and the solution approach [25]. Fuzzy sets, often integrated with machine learning methods, have been a weapon of choice in a wide range of computations intelligence applications [26-31]. In an effort to overcome traditional IDSS limitations under uncertainly, [32] proposed a Fuzzy Decision Support System that provides improved irrigation suggestions by combining IRRINET [14] with an inference system estimating the most suitable irrigation action to maintain soil moisture above a safe threshold prescribed level. [33] introduced a similar system focused on alfalfa, where max-min inference and rule-based Mamdani-type fuzzy modeling were adopted during variable fuzzification to generate irrigation scheduling.

Motivated by the relatively poor adoption of IDSS [17,32,33], despite the global impact that efficient irrigation could achieve, here, we aimed to develop an innovative irrigation decision support system for tree crops that can accept multiple conflicting objectives (e.g., water conservation and optimal yield) while considering a wide but very relevant range of system parameters such as soil moisture, plant evapotranspiration, weather conditions, agricultural input and water costs, as well as yield market value. The proposed methodology is applied to assess irrigation and olive tree crop management practices in Heraklion, in the island of Crete, Greece, which faces agricultural and water management challenges triggered by high demand, low water availability, and increased probability of extreme droughts [34], similarly to other Mediterranean islands.

\section{Methodology}

\subsection{System Definition}

The starting point for the probabilistic decision method is the classification of neighboring olive orchards that share common extrinsic conditions $E_{x}$ such as weather related factors and externalities (e.g., water price, cost per irrigation event, agricultural input costs, yield market value), but may differ in some intrinsic farm-specific conditions $I_{x}$ (e.g., soil type) as well as individual agricultural management strategies $S_{x}$ (e.g., crop management, irrigation pattern). These farms can be classified based on profit $P$ (the difference between revenue $R$ from selling yield $Y$ and $\operatorname{costs} \sum C_{x}$ incurred during cultivation) which is a function of the above:

$$
P=f\left(E_{x}, I_{x}, S_{x}\right),
$$

\subsection{Crop Yield}

Under optimal water and nutrient availability, climatic conditions, and crop management practices, crop yield $\mathrm{Y}$ and crop evapotranspiration reach a theoretical maximum. Reference [15] includes these 
parameters in a crop water production function and the respective relative decrease of yield to the relative reduction in evapotranspiration:

$$
Y_{a}=\left\{\begin{array}{r}
Y_{\max } \frac{E T_{a}}{E T_{c}}, E T_{a} \leq E T_{c} \\
Y_{\max }, E T_{a}>E T_{c}
\end{array},\right.
$$

where $Y_{\max }[\mathrm{t} / \mathrm{ha}]$ and $Y_{a}[\mathrm{t} / \mathrm{ha}]$ are the maximum and actual yield, and $E T_{c}[\mathrm{~mm}]$ and $E T_{a}[\mathrm{~mm}]$ are the maximum and actual evapotranspiration. This is a practical and common approach to estimate crop yield on an operational basis [35] as when other agronomical parameters are considered optimal, $E T_{a}$ can be equated with water requirements covered by precipitation and irrigation, and $E T_{c}$ with the crop's irrigation requirements. $E T_{\mathcal{c}}$ is a function of reference evapotranspiration $E T_{0}[\mathrm{~mm}]$ which represents the atmospheric water demand, a crop coefficient $K_{c}$ which accounts for agricultural management, crop type and phenology, and a water stress coefficient $K_{s}$ which accounts for root zone and soil water status [15]:

$$
E T_{c}=K_{s} K_{c} E T_{0},
$$

where $E T_{0}[\mathrm{~mm}]$ is typically assessed using physically based methods [36] but under data-scarce conditions, empirical formulas can be employed, such as Blaney-Criddle [37]:

$$
E T_{0}=\xi(0.46 \times T+8.13)
$$

where $\mathrm{T}\left[{ }^{\circ} \mathrm{C}\right]$ is the mean daily temperature and $\xi$ is the mean daily percentage of annual daytime hours. The crop coefficient $K_{c}$ can be estimated experimentally [38-44] or found in crop yield response factor datasets which are verified in the field [45]. For example, for olive trees, evapotranspiration (or irrigation), requirements are considered from March to November (Day of year 90-330) and, depending on agricultural management or crop type and phenology, may take different values, as shown in Figure 1.

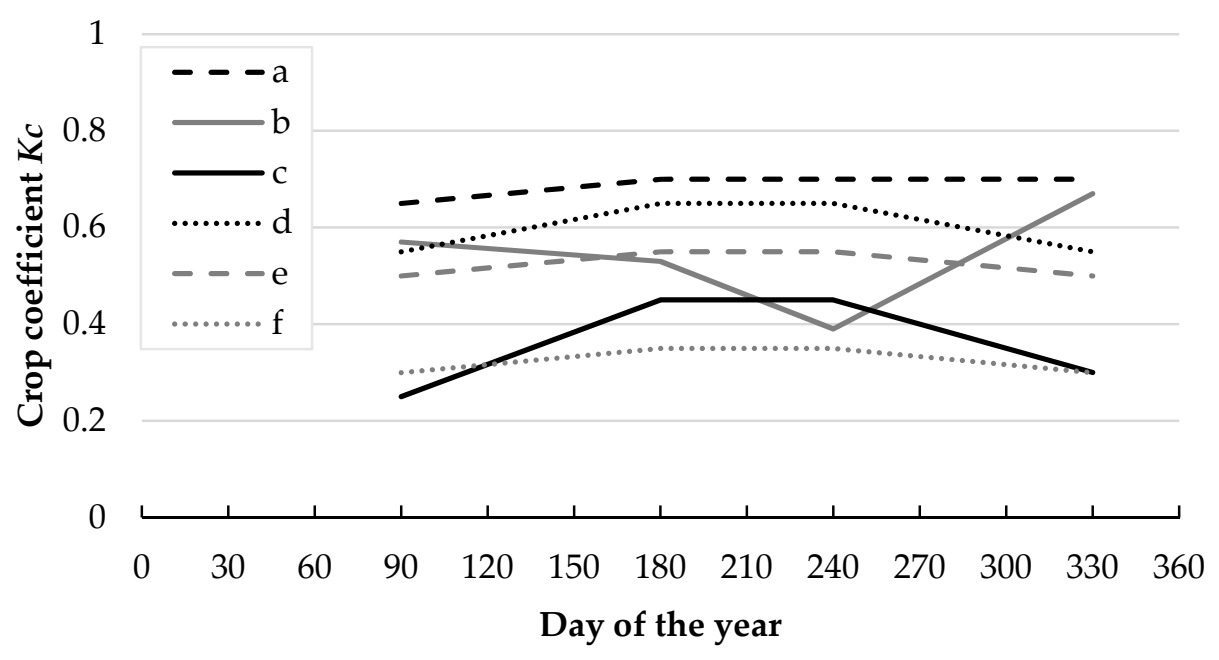

Figure 1. $K_{c}$ values from various sources: (a) [15], (b) [46], (c) HMA (1992), (d) [47]—High density, (e) [47]—Medium density, (f) [47]—Low density/young.

The value of water stress coefficient $K_{S}$ varies daily between 0 and 1 depending on soil moisture content $\theta\left[\mathrm{m}^{3} / \mathrm{m}^{3}\right]$ :

$$
K_{s}=\frac{\theta-\theta_{w}}{(1-p)\left(\theta_{f c}-\theta_{w}\right)}
$$

where $\theta_{f_{c}}\left[\mathrm{~m}^{3} / \mathrm{m}^{3}\right]$ and $\theta_{w}\left[\mathrm{~m}^{3} / \mathrm{m}^{3}\right]$ are the field capacity and wilting point of the soil, respectively, and $p$ is the fraction of potentially available soil moisture that can be depleted from the root zone or 
depth $Z_{r}$ before moisture stress occurs. Daily soil moisture $\theta(t)$ can be estimated using a simple water balance model that neglects the terms of runoff and groundwater:

$$
\theta(t) Z r=\theta(t-1) Z r+P(t)+I(t)-E T_{c}(t),
$$

On any day, water content $\theta(t)$ above field capacity $\theta_{f c}$ will drain below the root zone, whereas plant roots cannot extract quantities below wilting point $\theta_{w}$. It is due to this limitation that the farmer needs to consider irrigation scheduling for covering $E T_{c}$ requirements. For a more in-depth description, references $[15,48,49]$ elaborated more on this approach of irrigation scheduling.

\subsection{Strategies}

To take advantage of intrinsic farm conditions and reduce the uncertainty incurred by extrinsic conditions, a farmer can follow various strategies. Here, we consider crop management that can lead to small but significant changes of the crop coefficient $K_{c}$ such as heavy pruning $S_{P H}$ which can effectively reduce the evapotranspiration of tree crops $[50,51]$ versus light pruning $S_{P L}$. Furthermore, we consider that irrigation scheduling strategies $S_{I}$ can vary. Considering the limitation of $\theta$, the optimal scheduling strategy in terms of covering $100 \%$ of irrigation requirements is to take advantage of the soil's water buffering capacity and irrigate a quantity equal to exactly $\left(\theta_{f_{c}}-\theta_{w}\right) Z_{r}$ when $\theta=\theta_{w}$. The frequency of irrigation depends on the time required for $\theta$ to reach $\theta_{w}$ due to $E T_{c}$. Therefore, assuming zero precipitation, a farmer is required to schedule exactly $E T_{c} /\left(\left(\theta_{f_{c}}-\theta_{w}\right) Z_{r}\right)$ irrigation events. Nevertheless, as the farmer may also bear significant costs per water unit or/and per irrigation event, other strategic goals co-exist. Therefore, in an effort to increase profit, or merely achieve water conservation, other irrigation strategies may include reducing the amount of irrigated water per irrigation event by a fraction (i.e., $S_{I x \%}$ ) or reducing the amount irrigation events by $n$ times (i.e., $S_{I E-n}$ ).

\subsection{Simple Multicriteria Approach}

The idea of the multi-criteria approach is to use data which indirectly relate to crop yield [52]. The future crop yield states of a farm consist of the labels to be assigned to each farm after the implementation of alternatives scenarios:

$$
S=\{A, B, C, D, E\},
$$

For each scenario $a_{\mathrm{j}}$, we will subjectively assign a utility value $\mathrm{u}_{\mathrm{ji}}$ provided the resulting production yield after its implementation is $S_{i}(i=\mathrm{A}, \mathrm{B}, \mathrm{C}, \mathrm{D}, \mathrm{E})$. Utility values express the cost or advantage for each pair of alternative action-future state [53]. The factors defining each scenario's utility are normalized and combined with utility indexes for each potential state:

$$
\mathrm{u}_{\mathrm{ji}}=\left(\sum \text { normalized factor values }\right)_{j} * \text { utility }_{\mathrm{i}}, i \in S,
$$

The expected utility referred to alternative $j$ is [23]

$$
\mathrm{E}\left(\mathrm{u}_{\mathrm{j}}\right)=\sum_{\mathrm{i}=1}^{|S|} \mathrm{u}_{\mathrm{ji}} * \mathrm{p}\left(\mathrm{s}_{\mathrm{i}}\right),
$$

where $\mathbf{p}\left(\mathbf{s}_{\mathbf{i}}\right)$ expresses the likelihood among farm observations for the specific state. The decision choice will be pointed to the alternative that gave the highest expected utility:

$$
\mathrm{E}\left(\mathrm{u}^{*}\right)=\max _{\mathrm{j}} \mathrm{E}\left(\mathrm{u}_{\mathrm{j}}\right)
$$




\subsection{Multicriteria Approach with Posterior Information}

We can collect more data regarding future states so we can calculate in a safer way the probability for those events in set S (7). Suppose the elements of the "new" information are grouped together in set $C$. These elements can be used as posterior information in the previous approach to enhance the marginal probabilities. With the help of conditional probabilities, we can express the probability of posterior information given that a future state is true. These are the conditional probabilities of the type: $p\left(s_{i} \mid c_{k}\right)$.

That "new" information is often referred to as "imperfect information" because it attempts to express certainty (through conditional probabilities) by approximation in the future states' occurrence [54]. Typically, in decision-making problems, the type of "new" information is chosen to indirectly relate to future states. The more relevant the new information is to the actions we examine, the more reliable the decision can be considered [55].

\subsection{Multicriteria Fuzzy Approach}

The concept of participation in a set is fundamental in the representation of elements in a universe A [18]. The membership of an object in a crisp set is 0 or 1, but in fuzzy sets, we can assign infinite mappings to objects (belonging in universe A) in the range [0,1]. Fuzzy sets contain objects with ambiguous membership properties [23]. The fuzzy membership function embeds the mathematical formulation of the participation into a set and the representation is [25]

$$
\mu_{\tilde{\mathrm{A}}}(\mathrm{x}) \in[0,1]
$$

The value of (11) is the degree of membership for an element $\mathrm{x}$ in the fuzzy set $\widetilde{A}$. Assigning utility values in this manner like in the previous multicriteria subsection cannot be considered totally objective. We can introduce a more objective way to calculate utility for every irrigation scenario by taking into account the interaction among the three aforementioned utility factors as a combination value [56]. We will work with fuzzy logic on the simple multicriteria approach to see how it may alter those results.

First, a fuzzy set $\widetilde{\boldsymbol{F}}$ is defined with elements a predefined number of fuzzy states, e.g., excellent, good, moderate, etc.

The challenging part is defining the membership function. It will assign each combination-transition of events a value that describes the degree between $[0,1]$ which belong to the fuzzy linguistic variables.

In analogy to (9), the expected utility of each alternative is

$$
\mathrm{E}\left(\mathrm{u}_{\mathrm{j}}\right)=\sum_{\mathrm{m}=1}^{3} \mathrm{u}_{\mathrm{jm}} * \mathrm{p}\left(\widetilde{\mathrm{F}}_{\mathrm{m}}\right), m € \widetilde{\boldsymbol{F}}
$$

where [23]

$$
\mathrm{p}\left(\widetilde{\mathrm{F}}_{\mathrm{m}}\right)=\sum_{\mathrm{k}=1}^{\mathrm{n}} \mu_{\widetilde{\mathrm{F}}_{\mathrm{m}}}\left(\operatorname{trans}_{\mathrm{k}}\right) * \mathrm{p}\left(\operatorname{trans}_{\mathrm{k}}\right), \mathrm{m} € \widetilde{\boldsymbol{F}}, \mathrm{n}=\text { total combinations, }
$$

Equation (13) expresses the concept of the "probability of a fuzzy event". If a fuzzy event, $\widetilde{F}$ is crisp: $F$ the probability reduces to [23]

$$
\mathrm{p}(\mathrm{F})=\sum_{x_{k} \in F}^{n} p\left(x_{k}\right), \quad \mu_{F}=\left\{\begin{array}{rr}
1, & x_{k} \in F \\
0, & \text { otherwise }
\end{array}\right\},
$$

\subsection{Decision Tree and the ID3 Algorithm}

The concept in the multicriteria approach was to use data that are indirectly relevant to crop production. Decision trees are mechanisms for predictive modelling and are destined for supervised 
data mining that compute data in a multi-variate and tree-like fashion [57]. They result into object classification by splitting the branches of a tree. Each split corresponds to a test based on an attribute or a criterion. Those splits are called nodes and the first node is the root of the tree [58]. When the splitting procedure is terminated, it leaves at the end the terminal nodes or the "leaves" of the tree. The rules for object classification are provided by the branch sequences in the tree [59].

Decision trees give the ability to split a complex decision problem into a set of simpler decisions and classify objects with comprehensible representation [60] and challenging applications [61,62]. A formal definition of a typical classification problem can be described as follows. $\mathrm{S}$ is the set of objects in a training set in which each object is described by attributes [60]:

$$
A=\left\{A_{1}, \ldots, A_{N}\right\},
$$

The domain of each attribute Ai is represented by a set of discrete linguistic terms [60]:

$$
L\left(A_{i}\right)=\left\{A_{i}^{1}, \ldots, A_{i}^{n_{i}}\right\},
$$

Each object in $S$ is classified by a set of classes [60]:

$$
C=\left\{C_{1}, \ldots C_{k}\right\},
$$

The set of classes can be numerical values, ordered or unordered factors. The construction of a decision tree involves the following decisions [60]:

1. which is the next attribute to split,

2. when splitting is terminated, and

3. how to assign terminal nodes to a class.

The ID3 (Interactive Dichotomizer 3) algorithm is a quite popular decision tree induction algorithm [60]. It works with an entropy information measure in order to evaluate the discriminatory power of each attribute. It works well and fast with few attributes and small training data sets and has advantages such as understandable decision rules and an intuitive model [63]. Other famous algorithms like C4.5 and Classification-Regression Tree (CART) have been developed based on ID3 [58,63]. ID3 exploits information gain values for each attribute to build a tree. The attribute with the greatest information gain on the decision is primarily selected [58]. Entropy is calculated as follows. The greatest information gain will lead to the greatest decrease in entropy [60]:

$$
E(S)=\sum_{k=1}^{K}-p(k) * \log _{2} p(k)=\sum_{k=1}^{K}-\frac{\left|C_{k}\right|}{|S|} * \log _{2} \frac{\left|C_{k}\right|}{|S|}
$$

where $E(S)$ represents the entropy and $p(k)$ is the relative frequency of class $k$ in set $\mathrm{S}$, i.e., it is the ratio of the objects in class $\mathrm{k}$ to the whole set $\mathrm{S}$ : In all computations, $0{ }^{*} \log _{2} 0$ is assumed as 0 . If decisions for all objects are the same, then entropy will be zero. This means that it is not necessary to split the node on the corresponding decision level [60]. Every time a split is done, $\mathrm{S}$ is updated. If $\mathrm{E}(\mathrm{S})=0$ or no attribute remains to be split, then this branch is terminated. If all branches are terminated, then classification is complete. Let $T i$ be the set of subsets created from splitting set $S$ by attribute Ai: Information gain for each attribute is computed as follows [60]:

$$
I G\left(S, A_{i}\right)=E(S)-\sum_{t \in T_{i}} p(t) * E(t)=E(S)-\sum_{t \in T_{i}} \frac{|t|}{|S|} * E(t)
$$


and entropy for subset $t$ :

$$
E(t)=\sum_{k=1}^{K}-p\left(t_{k}\right) * \log _{2} p\left(t_{k}\right)=\sum_{k=1}^{K}-\frac{\left|t_{k}\right|}{|t|} * \log _{2} \frac{\left|t_{k}\right|}{t}, \quad \text { where } t=\bigcup_{k=1}^{K} t_{k}
$$

At each iteration of ID3 algorithm, the attribute with the highest information gain is selected as the decision level.

\subsection{Decision Variable Importance}

Gini is one of the most widely applied impurity functions, providing a measure of the "goodness-of-split" for decision trees by promoting "splits that allocate a single pure node for the largest class and the rest for the remaining classes" [64]. The Gini index for a node $t$ can be calculated as

$$
I_{G}(t)=\sum_{i \neq j}^{c} p(i \mid t) p(j \mid t)=1-\sum_{j}^{c} p(j \mid t)^{2}
$$

where $c$ is the number of classes and $p(i \mid t), p(j \mid t)$ are the estimated probabilities of classes $i, j$ at node $t$ [65-67].

\section{Case Study}

\subsection{Study Area}

The island of Crete, Greece, has a typical Mediterranean island environment, with about $53 \%$ of the annual precipitation occurring in the winter, $23 \%$ during autumn and $20 \%$ during spring, covering most irrigation requirements, while there is almost no rainfall during summer [68,69]. The average precipitation for a normal year is approximately $934 \mathrm{~mm}$ or $7697 \mathrm{Mm}^{3}$ [70], but the nonuniform distribution in space (a negative gradient of almost $300 \mathrm{~mm}$ from west to east and a strong orographic effect) and time (dry summers) makes dry season precipitation a very small but crucial portion of the total supply [71]. Figure 2 and Table 1 show dry season (March to November) weather parameters for three characteristic years-dry, normal and wet-with probabilities of occurrence equal to $20 \%, 60 \%$ and $20 \%$.

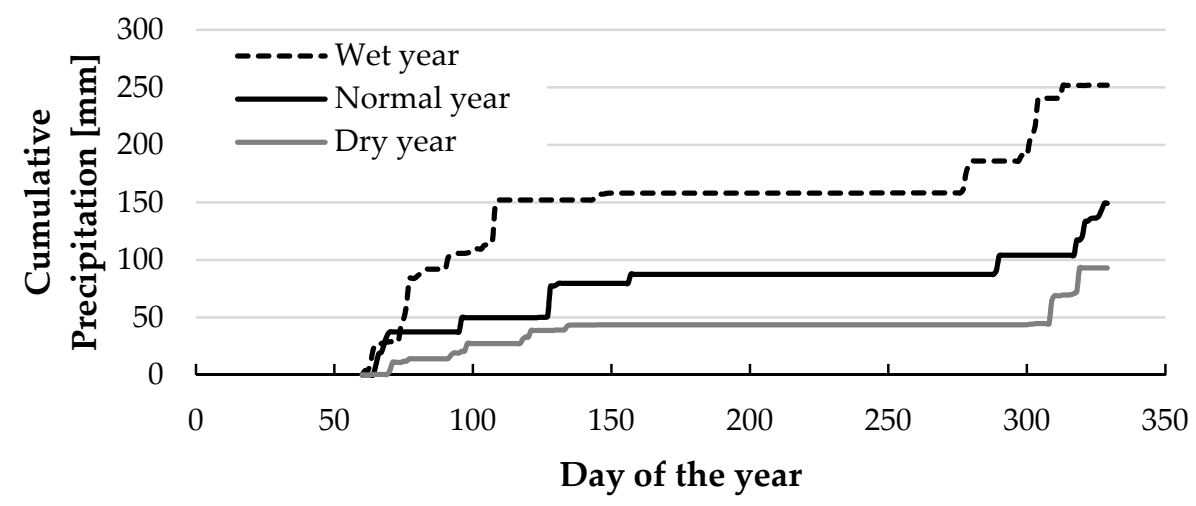

Figure 2. Cumulative precipitation at the station of Moires, Crete, during the dry season (March to November) for a Dry (D), Normal, and Dry (D) year.

On the other hand, agriculture is the major water consumer (81.2\%), with olive trees (Olea europea, L. cv Koroneiki) being the most widespread crop, accounting for $64.2 \%$ of the agricultural land and $86 \%$ of all tree crops ( 35 million trees producing $120 \mathrm{kt}$ of olive oil) [72]. Currently, olive tree irrigation is mainly empirical, often without scientific documentation and guidance. This is due to the resilient characteristic of the olive tree which demonstrates sustainable yield even under rainfall conditions 
while also showing minimal immediate impacts under over-irrigation [73], but also due to favorable irrigation water pricing. Therefore, even though only $65 \%$ of irrigated water covers crop transpiration requirements [74] and there is evidence that $34 \%$ can drain under the root zone [75], the majority of farmers do not apply optimal irrigation scheduling that could lead to significant conservation of water resources [76].

Table 1. Total precipitation and average temperature $T$ at the station of Moires, Crete, during the dry season (March to November) for a Dry (D), Normal, and Dry (D) year and respective total $E T_{0}$ values calculated using Blaney-Criddle [37].

\begin{tabular}{cccc}
\hline Scenario & $\begin{array}{c}\text { Total Precipitation * } \\
{[\mathbf{m m}]}\end{array}$ & $\begin{array}{c}\text { Average Temperature } \\
{\left[{ }^{\circ} \mathbf{C}\right]}\end{array}$ & $\begin{array}{c}\text { Total Reference } \\
\text { Evapotranspiration }[\mathbf{m m}]\end{array}$ \\
\hline Wet year $(\mathrm{W})$ & 251.9 & 20.7 & 1347.8 \\
Normal year $(\mathrm{N})$ & 149.2 & 21.1 & 1361.3 \\
Dry year $(\mathrm{D})$ & 93 & 21.4 & 1374.9 \\
\hline
\end{tabular}

* March to November.

\subsection{Argicultural Input and Water Cost}

For the cultivation of olive trees, agricultural input $\operatorname{cost} C_{a}[€ / \mathrm{ha}]$ was classified into pruning, tilling, pesticide and fertilizer application, and crop picking, which are all functions of the cultivated area and amount to $3000 € /$ ha [77]. Agricultural water service cost recovery in Crete is among the highest in Greece, with $56.3 \%$ of the financial and environmental cost being recovered [78]. This means that in essence, agricultural water is among the most expensive in Greece and in most cases, prices range between 0.05 and $0.23 € / \mathrm{m}^{3}$ with an average (normalized per distributed $\mathrm{m}^{3}$ ) of $0.13 € / \mathrm{m}^{3}$ [79] or $13 \mathrm{~mm} / \mathrm{ha}$ irrigated, depending on water scarcity or quality. Here, we tested three low-to-moderate price scenarios of $0.05,0.10$, and $0.18 € / \mathrm{m}^{3}$ assuming that under high demand or climate change conditions, values will increase. Additionally, we considered that each irrigation event causes an additional expense of $50 €$ /event.

\subsection{Crop Yield}

Although olive trees can sustain adequate yield under low annual water supply, irrigation during the dry period is indispensable when aiming for high yields [80]. In a farm-scale study under various irrigation scenarios, the cv. Koroneiki cultivated in the study area had a fruit yield between 4.8 and $7.6 \mathrm{t} / \mathrm{ha}$ (considering a typical plating density of 200 trees/ha) [81]. Information from 35 municipal units of Heraklion (LAU 2 level) from the Hellenic Statistical Authority (HSA) [72] for the period 2002-2007 confirm this measurement, producing a slightly larger yield range (Figure 3). As this sample was considered more representative and focuses on a relatively recent and financially stable period for Greece (i.e., after entering the eurozone and before the financial crisis), it was used to define the prior probability distribution of yield $Y$ for the case study. $Y$ was divided into five (Table 2 ) and three classes (Table 4) for the simple and the fuzzy multicriteria approach, respectively. Moreover, in accordance with Equation (2), the results of [81] show a reduction of $Y_{a}$ by $40 \%$ for a rainfed treatment where about $50 \%$ of the total $E T_{c}$ requirements were covered. Above a certain threshold, $Y_{a}$ gains are no longer statistically significant. Here, we consider that wet season precipitation covers at least $50 \%$ of the annual $E T_{c}$; therefore, irrigation strategies refer to a fraction of the remaining irrigation requirements. The unit price of the yield is considered fixed at $2.5 € /$ ha, based on recent Extra Virgin Olive Oil prices [82]. 


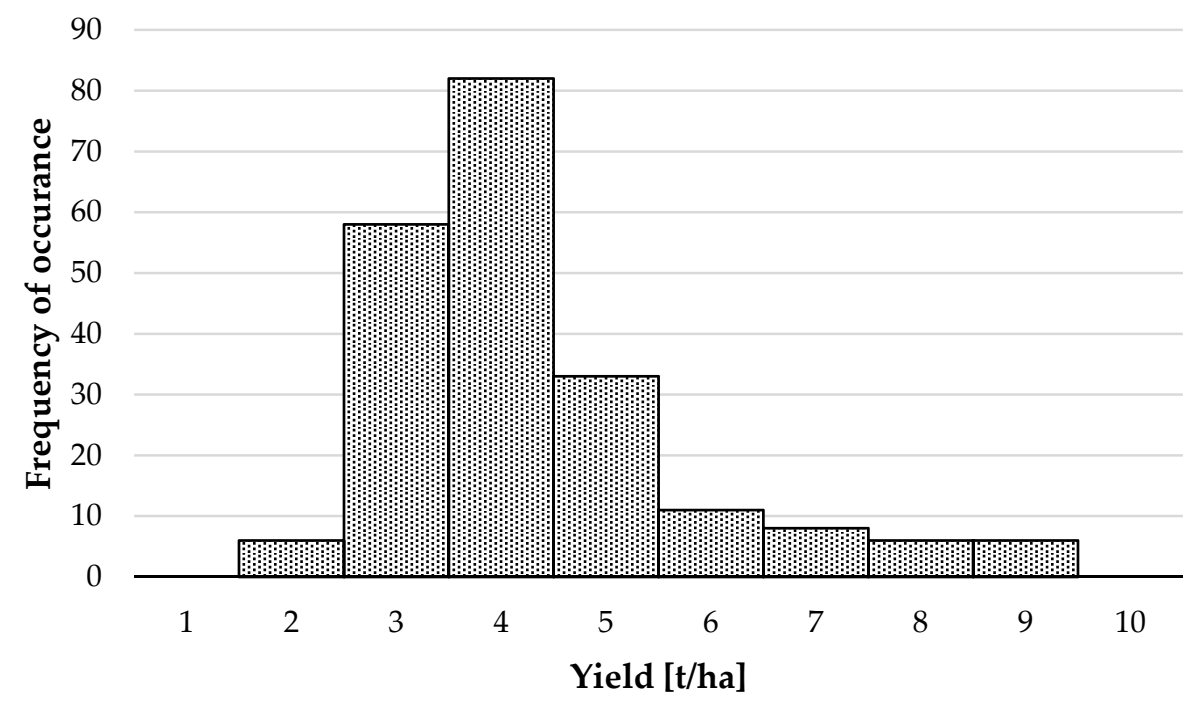

Figure 3. Histogram of olive tree farm yield [t/ha] for selected municipal units of Heraklion, Crete, for the period 2000-2007 [72].

Table 2. Crop yield classes and likelihood of occurrence based on [72].

\begin{tabular}{ccc}
\hline Yield Class & Yield Range [t/ha] & Likelihood $\mathbf{p}\left(\mathbf{s}_{\mathbf{i}}\right)$ \\
\hline E & {$[1,2]$} & 0.024 \\
D & {$[2,4]$} & 0.667 \\
C & {$[4,6]$} & 0.214 \\
B & {$[6,8]$} & 0.067 \\
A & $\geq 8$ & 0.029 \\
\hline
\end{tabular}

\subsection{Alternative Conditions and Strategies}

To incorporate a wider range of alternative scenarios and strategies, the cropping system was modeled for three soil types (Table 4), three climatic conditions (Table 1), two crop management practices for high and low $K_{c}$, and nine irrigation strategies (Table 3). Regarding $K_{c}$, values from the Hellenic Ministry of Agriculture [83] were used (two management practices, light pruning/heavy pruning). The irrigation strategies presented in Table 3 are a combination of reduced irrigation with respect to the optimal $\left(\theta_{f c}-\theta_{w}\right) Z_{r}$, considering an average $Z_{r}$ of $1.2 \mathrm{~m}$ and p equal to 0.6 [49], and reduced irrigation events.

Table 3. Modeled irrigation strategies relative to the optimum irrigation amount per irrigation event $S_{I x \%}$ and to the optimum number of irrigation events $S_{I E-n}$.

\begin{tabular}{ccc}
\hline Scenario & Relative Irrigation & Reduction of Irrigation Events \\
\hline 1 & $100 \%$ & 0 \\
2 & $75 \%$ & 0 \\
3 & $50 \%$ & 0 \\
4 & $100 \%$ & 1 \\
5 & $75 \%$ & 1 \\
6 & $50 \%$ & 1 \\
7 & $100 \%$ & 2 \\
8 & $75 \%$ & 2 \\
9 & $50 \%$ & 2 \\
\hline
\end{tabular}


Table 4. Soil moisture at field capacity $\left(\theta_{f_{\mathcal{c}}}\right)$ and wilting point $\left(\theta_{w}\right)$ for texture classes at $2.5 \% \mathrm{w}$ organic matter (OM), no salinity, gravel or density adjustment (values after [84]).

\begin{tabular}{ccc}
\hline Soil Texture Class & $\boldsymbol{\theta}_{f c}$ & $\boldsymbol{\theta}_{\boldsymbol{w}}$ \\
\hline Loamy Sand (LS) & 0.15 & 0.07 \\
Sandy Loam (SL) & 0.23 & 0.11 \\
Clay (Cl) & 0.36 & 0.22 \\
\hline
\end{tabular}

Table 3 shows the different irrigation scenarios comprised of combinations of irrigation amount and frequency relative to the amount prescribed by FAO-56.

\subsection{Simple Multicriteria Approach}

The factors defining each scenario's utility were chosen to be

1. The relative amount (in percentage) of the disposed water used during the irrigation compared to the full-scale irrigation in order to reach the field capacity $(100 \%, 75 \%, 50 \%)$.

2. The reduction in frequency (number of irrigation times) during the cultivation season compared to the number recommended for maximum crop yield (recommended n -1, recommended n-2).

3. The profit from the farm. This is calculated by subtracting the costs of irrigation from the revenue from selling the crop.

The amount and frequency recommendations are provided by Equation (3) and they are calculated based on soil and plant parameters described previously in order to achieve the best yield possible. For the first factor, the full irrigation $(100 \%)$ is taken as reference. It is considered as the irrigation performed in full scale to the farm which is adequate to reach the field capacity. The frequency refers to how many times it is recommended to visit and irrigate the farm throughout the cultivation season with the proposed water amount. Optimally, we want to have the least amount of water consumed on the farm with the fewest visits for irrigation. The third factor conflicts with the first two and this makes the decision process more interesting. The more we irrigate, the more we spend on water. This may lead to a higher crop yield but also a higher cost, but the profit will reflect this tradeoff. The challenge in this approach was to build the utility values by exploiting relevant information and not pure crop measurements.

Initially, a utility index is attributed to each future state:

$$
\mathrm{A} \rightarrow 10 \quad \mathrm{~B} \rightarrow 8 \quad \mathrm{C} \rightarrow 5 \quad \mathrm{D} \rightarrow 2 \quad \mathrm{E} \rightarrow 0.5
$$

The values for the three utility factors are normalized in the range [0,1]. The sum of the three normalized values is multiplied by the corresponding utility index and thus, the utility value is determined [85]:

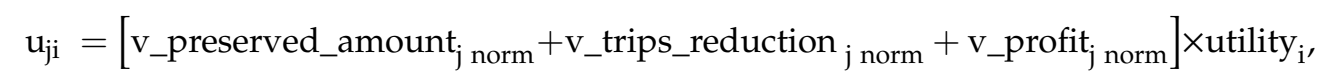

In Equation (22), a non-successive numbering was arbitrarily chosen; thus, patterns with close values on water preservation and irrigation frequency can still hold the lead if they refer to higher profit.

The challenge examined in this paper is to enhance the utility with adjacent parameters which will affect the decision in an objective manner.

The expected utility referred to alternative $\mathrm{j}$ is [86]

$$
\mathrm{E}\left(\mathrm{u}_{\mathrm{j}}\right)=\sum_{\mathrm{i}=1}^{5} \mathrm{u}_{\mathrm{ji}} \times \mathrm{p}\left(\mathrm{s}_{\mathrm{i}}\right),
$$


The decision will then point to the alternative with the highest expected utility:

$$
E\left(u^{*}\right)=\max _{j}\left(u_{j}\right)
$$

The likelihood of occurrence $\left(\mathrm{p}\left(\mathrm{s}_{\mathrm{i}}\right)\right)$ for the various crop yields is given by data by the Hellenic Statistical Agency and address olive farms in the island of Crete. The data are presented in Table 5.

Table 5. Statistics of crop yield for Olive Farms in Crete.

\begin{tabular}{cc}
\hline Yield Label & Likelihood $\mathbf{p}\left(\mathbf{s}_{\mathbf{i}}\right)$ \\
\hline A & 0.029 \\
\hline B & 0.067 \\
\hline C & 0.214 \\
\hline D & 0.667 \\
\hline E & 0.024 \\
\hline
\end{tabular}

\subsection{Multicriteria Approach with Posterior Information}

In order to assist the decision on which irrigation patterns to propose for improving the crop yield, we chose, as "new" information, the climate conditions. Thus, we explore the likelihood of a farm achieving a certain crop state depending on whether it was a wet, normal or dry year. The statistical data for precipitation are presented in Table 6.

Table 6. Statistics of precipitation in Crete.

\begin{tabular}{cc}
\hline Precipitation & Likelihood $\mathbf{p}\left(\mathbf{c}_{\mathbf{k}}\right)$ \\
\hline Dry & 0.2 \\
\hline Normal & 0.6 \\
\hline Wet & 0.2 \\
\hline
\end{tabular}

The expected utility that refers to the alternative $\mathrm{j}$ under the condition of "new" information is then:

$$
E\left(u_{j} \mid c_{k}\right)=\sum_{i=1}^{n} u_{j i} \times p\left(s_{i} \mid c_{k}\right), n=5
$$

And the maximum expected utility:

$$
E\left(u^{*} \mid c_{k}\right)=\max _{j} E\left(u_{j} \mid c_{k}\right)
$$

To determine the maximum unconditional expected utility for each alternative in (26), the marginal probability is used:

$$
E\left(u_{x}^{*}\right)=\sum_{k=1}^{r} E\left(u^{*} \mid c_{k}\right) \times p\left(c_{k}\right), r=3
$$

In Equation (28), $r$ is the cardinality of the "new" information and equals to the number of weather conditions (here dry, normal, and wet, so equal to 3 ).

\subsection{Multicriteria Fuzzy Approach}

For the olive farms, a fuzzy set $\widetilde{F}$ is defined with elements the following three fuzzy states:

- $\quad$ Excellent application (Fuzzy Element 1). 
- Good application (Fuzzy Element 2).

- Moderate application (Fuzzy Element 3).

The next step is to choose the factors which will form the meaning of the fuzzy states. Then, we can assign numerical values to the irrigation scenarios depending on how they perform in relation to the verbal fuzzy variables. The idea was to take into account the estimated profit, the relative irrigation and the trips reduction factors and build a scoring matrix.

Profit is divided into three groups based on the values calculated for all possible cases (low, medium, and high). Next, scoring is done by summing the scoring values for the profit, the relative irrigation water amount and the reduction in frequency of irrigations. The optimal case is that where we have a maximum increase in yield with the $50 \%$ preservation in water and a reduction by 2 on the optimal irrigation times while we achieve a high profit. The relative irrigation amount is grouped into three groups-50\%, $75 \%$ and $100 \%$-and the possible scorings span from 1 to 3 , respectively. The same goes for the trips reduction times: $\mathrm{n}-0 \rightarrow 1, \mathrm{n}-1 \rightarrow 2, \mathrm{n}-2 \rightarrow 3$, and the profit: low $\rightarrow 1$, medium $\rightarrow 2$, high $\rightarrow 3$. Thus, a scenario which preserves $75 \%$ of water will add 2 to the total score. If it achieves that with a reduction of irrigation events by 2 , another 3 is added to the total score. If it achieves low profit after applying the irrigation scenario, only 1 will be added. Note that in the absence of more information, scoring here is assigned arbitrarily but in a real circumstances, the water manager may assign asymmetric scores.

The above values represent the scoring of each case, which will shape the membership in each fuzzy variable. The lower and upper value for each fuzzy variable define the intervals which will form the boundaries among those states. Because scoring takes into account profit, relative irrigation amount, and reduction in irrigation frequency, the fuzzy variables' definition is represented by the combination of those three factors. The cardinality of occurrence among the scoring values as well as minimum and maximum scorings are important in defining the numeric participation ranges. Those will express the values where a combination is or is not a match for each verbal fuzzy state. From Table 7, we observe that most occurrences are in the scoring range between 5 and 7 . Those scores will be considered as "good" performances. The rest of the scoring in the lower and upper space will reflect "moderate" and "excellent" scorings, respectively. The numerical ranges which represent exact matches for the linguistic fuzzy variables are given in Table 8.

Table 7. Fuzzy Scorings.

\begin{tabular}{|c|c|c|c|c|c|c|c|c|c|}
\hline $\begin{array}{l}\text { Irrigation Strategy } \\
\text { Profit }\end{array}$ & $50 \% / n-2$ & $50 \% / n-1$ & $50 \% / \mathbf{n}$ & $75 \% / n-2$ & $75 \% / n-1$ & $75 \% / n$ & $100 \% / n-2$ & $100 \% / n-1$ & $100 \% / n$ \\
\hline Low & 7 & 6 & 5 & 6 & 5 & 4 & 5 & 4 & 3 \\
\hline Medium & 8 & 7 & 6 & 7 & 6 & 5 & 6 & 7 & 4 \\
\hline High & 9 & 8 & 7 & 8 & 7 & 6 & 7 & 8 & 5 \\
\hline
\end{tabular}

Table 8. Fuzzy scorings ranges.

\begin{tabular}{cc}
\hline Profit Class & Total Score Range \\
\hline Moderate & {$[1,5)$} \\
Good & {$[5,7]$} \\
Excellent & $(7,9]$ \\
\hline
\end{tabular}

The degree of membership of an element in each fuzzy variable will vary depending on the association of its score and the exact verbal match of the given fuzzy variable. For example, an application with a score of 5 is a match for a "good" application but in the fuzzy world, it will have a smaller degree of membership in the neighbor fuzzy variables. For this example, a small participation in the "moderate" fuzzy set is expected but a scoring of 5 is not expected to belong in the "excellent" set. The membership function we will choose must reflect this logic. Many popular membership functions 
are used in fuzzy decision making (triangular, trapezoidal, Gaussian) [87]. We chose the triangular membership function for its simplicity but also because we have a small non-continuous numerical set of scores. The triangular membership function will assign lower memberships in neighboring fuzzy variables for a given score and will also assign the highest membership to scores which are in the middle of the range for each fuzzy state [19]. After forming those intervals, we use the triangular membership function [19] to determine values for the scenarios in linguistic terms.

$$
\begin{gathered}
\mu_{\text {moderate }}(x)= \begin{cases}1, & 1 \leq x \leq 4 \\
(6-x) / 2, & 4<x<6 \\
0, & x \geq 6\end{cases} \\
\mu_{\text {good }}(x)= \begin{cases}0, & x \leq 4 \\
(x-4) / 2, & 4<x \leq 6 \\
(8-x) / 2, & 6<x<8 \\
0, & x \geq 8\end{cases} \\
\mu_{\text {excellent }}(x)= \begin{cases}0, & x \leq 6 \\
(x-6) / 2, & 6<x<8 \\
1, & 8 \leq x \leq 9\end{cases}
\end{gathered}
$$

The assignment of utility values will now be made on the three fuzzy future states of the set $\widetilde{F}$ in a similar way as for the non-fuzzy states in (22):

$$
\left.\widetilde{\mathrm{F}}_{1 \text { (moderate) })^{a 1}} \quad \widetilde{\mathrm{F}}_{2(\text { good })}{ }^{a 2} \quad \widetilde{\mathrm{F}}_{3 \text { (excellent) }}\right)^{a 3}
$$

Equation (32) indicates that utility is doubled for "good" applications and is tripled for "excellent" applications. No special weighting was assigned to the fuzzy states in order to let the fuzzy scoring operate and result into utilities with a more objective manner than the simple multicriteria approach. Based on (12), the fuzzy utility matrix will be calculated.

\subsection{Shortcomings of Probabilistic Approaches}

In the previous sections, we looked into probabilistic approaches to the problem which mainly exploit statistical data. Conditional probabilities can help examine the utilities given the new facts. Multicriteria approaches while exploiting posterior information are used in diverse areas such as public health, energy conservation and economics [24,88-90]. Suppose we are looking for the chances of achieving crop yields in various weather conditions. If the event of achieving a high yield is $\mathrm{P}(\mathrm{H})$, the event of applying medium irrigation is $\mathrm{P}(\mathrm{I})$ and the event of a wet period is $\beta$, then the combined conditional probabilities can be expressed as [55]

$$
P(H \mid I, \beta)=P(H \mid C),
$$

We assume that

$$
(I \cap \beta)=C,
$$

so,

$$
P(H \mid C)=\frac{P(H \cap C)}{P(C)},
$$

and

$$
\frac{P(H \cap C)}{P(C)}=\frac{P(H \cap(I \cap \beta))}{P(I \cap \beta)},
$$


therefore,

$$
P(H \mid I, \beta)=\frac{P(H \cap I \cap \beta)}{P(I \cap \beta)},
$$

We will be needing the cases where all the events co-occur and also cases which show what irrigation plans are independently chosen in the occurrence of the possible rain conditions. This logic can be expanded to accommodate additional attributes. We will be needing accordingly the likelihood where those events co-occur. But when we look at a specific irrigation combined with precipitation, we understand that those events are not mutually exclusive, nor are they independent.

This means [54] that

$$
P(I \cap \beta) \neq \varnothing \text { and } P(I \mid \beta) \neq P(I),
$$

The likelihood of applying an irrigation scheme is affected by the likelihood of rain and the disadvantage is that the approach lacks the ability to present a correlation of the attributes. It is not necessarily about prioritizing and weighting the effect one attribute can have on the result but examining sequences that cause actions that depend on the occurrence of an attribute. Let us examine the method of decision trees on our problem which allows us to examine multiple attributes together [58] and also build paths that lead to classifying selling profit given the circumstances which can occur. The goal is to achieve a classification of examples that will point to the proper decision in a given combination of parameters [58].

\subsection{Decision Tree and the ID3 Algorithm}

For the irrigation decision problem, the following attributes will be examined:

1. Soil type. Possible soil types are loamy sand, sandy loam, and clay.

2. Weather during cropping season. Wet, normal, and dry.

3. Management practices. They are chosen to be: M1 heavy pruning and M2 light pruning. Tree pruning may bring down the total production, but it is a wise choice during a dry year (low in precipitation).

4. The irrigation amount as a percentage of the recommended amount per irrigation event.

5. The reduction in irrigation events related to the recommended.

The class on which classification is performed is profit rather than crop yield since, as discussed in Equation (1) and Sections 3.2 and 3.3, profit is also a function of water cost, yield price and other operational costs. Thus, crop yield alone is not representative of how well we did in our decision process. The idea is to study multiple attributes together and how their selection leads to a more refined decision compared to evaluating them independently [91].

Finally, to quantify the sensitivity of the decision tree to each variable, the tree was trained over 1000 iterations presented with only $70 \%$ of the samples each time. The Gini importance, quantifying the importance of each variable, was calculated for each resulting tree. To allow a comparison between iterations, for each run Gini, importance values were normalized so that their sum totaled 100.

\section{Results and Discussion}

\subsection{Simple Multicriteria Approach}

Table 9 shows the results for the simple multicriteria approach based on Equations (22)-(24), where the last strategy is the optimal. The reason this strategy has high utility is that it performs really well regarding the three multicriteria factors. It consumes the lowest amount of water combined with the fewer trips to the farm. Although it spends the least amount of water, it causes medium crop yield and this is reflected on the profit. Moreover, scenarios with a lower irrigation amount and irrigation event frequency values ( 5 and 6 ) perform very well. This shows that we can achieve satisfying profits without using high irrigation amounts and without frequent irrigation events. The three first scenarios 
share the same low utility, showing that regardless of the amount, not reducing the frequency is not favored in decision making.

Table 9. Utility values matrix for irrigation scenarios.

\begin{tabular}{cccccccccc}
\hline $\begin{array}{c}\text { Scenario } \\
\rightarrow\end{array}$ & $\mathbf{1}$ & $\mathbf{2}$ & $\mathbf{3}$ & $\mathbf{4}$ & $\mathbf{5}$ & $\mathbf{6}$ & $\mathbf{7}$ & $\mathbf{8}$ & $\mathbf{9}$ \\
\hline$E\left(\boldsymbol{a}_{j}\right)$ & 3.242 & 3.242 & 3.242 & 3.6341 & 4.8799 & 4.9742 & 4.0259 & 5.6277 & $\mathbf{6 . 5 1 7 3}$ \\
\hline
\end{tabular}

\subsection{Multicriteria Approach with Posterior Information}

With the help of conditional probabilities (Table 10), we can express the relation of estimated crop yield and rainfall. The probability $\mathrm{p}\left(\mathrm{s}_{\mathrm{i}} \mid \mathrm{c}_{\mathrm{k}}\right)$ expresses the probability of the farm yielding to a crop label when the specific precipitation degree is observed. In this case study, the estimates were produced using Equation (3).

Table 10. Conditional probabilities for precipitation.

\begin{tabular}{cccc}
\hline Precipitation State & DRY & NORMAL & WET \\
\hline$p\left(A \mid c_{k}\right)$ & 0.1667 & 0.1667 & 0.1296 \\
\hline$p\left(B \mid a_{k}\right)$ & 0.8333 & 0.8333 & 0.7037 \\
\hline$p\left(C \mid c_{k}\right)$ & 0 & 0 & 0.1667 \\
\hline$p\left(D \mid c_{k}\right)$ & 0 & 0 & 0 \\
\hline$p\left(E \mid c_{k}\right)$ & 0 & 0 & 0 \\
\hline
\end{tabular}

The variation of results should be mathematically represented in every column by displaying a distribution of the probabilities values among more than one crop yield label. Those probabilities (which express estimates) should therefore be less than 1 and be allocated to the adjacent crop yield labels where the farm is about to move to [55]. The sum of each column's probabilities is equal to 1 [55]. Table 11 shows the results. We notice that the last alternative would be chosen again. Scenarios 5 and 6 still perform very well. However, we observe that scenarios with no water preservation in mind like scenarios 1-3 are left behind with a higher distance from the winners. This shows that the use of rainfall as posterior information helped into distinguishing in a more clear way the best from the worse scenarios.

Table 11. Utility values matrix given climate conditions.

\begin{tabular}{cccccccccc}
\hline $\begin{array}{c}\text { Scenario } \\
\rightarrow\end{array}$ & $\mathbf{1}$ & $\mathbf{2}$ & $\mathbf{3}$ & $\mathbf{4}$ & $\mathbf{5}$ & $\mathbf{6}$ & $\mathbf{7}$ & $\mathbf{8}$ & $\mathbf{9}$ \\
\hline $\boldsymbol{E}\left(\boldsymbol{a}_{\boldsymbol{j}}\right)$ & 8.3334 & 8.3334 & 8.3334 & 9.3409 & 12.5435 & 12.5435 & 10.3484 & 14.4659 & 16.7527 \\
\hline
\end{tabular}

\subsection{Multicriteria Fuzzy Approach}

In Table 12, the membership values for each one of the 27 irrigation per yield combinations are presented. Based on (13), the probabilities for the fuzzy events (Table 13) are calculated: 
Table 12. Fuzzy membership values and probabilities.

\begin{tabular}{|c|c|c|c|c|c|c|c|c|c|}
\hline $\begin{array}{l}\text { Irrigation Strategy } \\
\text { Profit }\end{array}$ & $50 \% / n-2$ & $50 \% / n-1$ & $50 \% / n$ & $75 \% / n-2$ & $75 \% / n-1$ & $75 \% / n$ & $100 \% / n-2$ & $100 \% / n-1$ & $100 \% / n$ \\
\hline Low & $\begin{array}{c}\mu_{\text {mod }}=0 \\
\mu_{\text {good }}=1 / 2 \\
\mu_{\text {exc }}=1 / 2\end{array}$ & $\begin{array}{c}\mu_{\text {mod }}=0 \\
\mu_{\text {good }}=1 \\
\mu_{\text {exc }}=0\end{array}$ & $\begin{array}{c}\mu_{\text {mod }}=1 / 2 \\
\mu_{\text {good }}=\frac{1}{2} \\
\mu_{\text {exc }}=0\end{array}$ & $\begin{array}{c}\mu_{\text {mod }}=0 \\
\mu_{\text {good }}=1 \\
\mu_{\text {exc }}=0\end{array}$ & $\begin{array}{c}\mu_{\text {mod }}=1 / 2 \\
\mu_{\text {good }}=\frac{1}{2} \\
\mu_{\text {exc }}=0\end{array}$ & $\begin{array}{c}\mu_{\text {mod }}=1 \\
\mu_{\text {good }}=0 \\
\mu_{\text {exc }}=0\end{array}$ & $\begin{array}{c}\mu_{\text {mod }}=1 / 2 \\
\mu_{\text {good }}=\frac{1}{2} \\
\mu_{\text {exc }}=0\end{array}$ & $\begin{array}{c}\mu_{\text {mod }}=1 \\
\mu_{\text {good }}=0 \\
\mu_{\text {exc }}=0\end{array}$ & $\begin{array}{c}\mu_{\text {mod }}=1 \\
\mu_{\text {good }}=0 \\
\mu_{\text {exc }}=0\end{array}$ \\
\hline Medium & $\begin{array}{c}\mu_{\text {mod }}=0 \\
\mu_{\text {good }}=0 \\
\mu_{\text {exc }}=1\end{array}$ & $\begin{array}{l}\mu_{\text {mod }}=0 \\
\mu_{\text {good }}=\frac{1}{2} \\
\mu_{\text {exc }}=1 / 2\end{array}$ & $\begin{array}{c}\mu_{\text {mod }}=0 \\
\mu_{\text {good }}=1 \\
\mu_{\text {exc }}=0\end{array}$ & $\begin{array}{l}\mu_{\text {mod }}=0 \\
\mu_{\text {good }}=\frac{1}{2} \\
\mu_{\text {exc }}=1 / 2\end{array}$ & $\begin{array}{c}\mu_{\text {mod }}=0 \\
\mu_{\text {good }}=1 \\
\mu_{\text {exc }}=0\end{array}$ & $\begin{array}{c}\mu_{\text {mod }}=\frac{1}{2} \\
\mu_{\text {good }}=\frac{1}{2} \\
\mu_{\text {exc }}=0\end{array}$ & $\begin{array}{c}\mu_{\text {mod }}=0 \\
\mu_{\text {good }}=1 \\
\mu_{\text {exc }}=0\end{array}$ & $\begin{array}{l}\mu_{\mathrm{mod}}=0 \\
\mu_{\mathrm{good}}=\frac{1}{2} \\
\mu_{\mathrm{exc}}=1 / 2\end{array}$ & $\begin{array}{c}\mu_{\text {mod }}=1 \\
\mu_{\text {good }}=0 \\
\mu_{\text {exc }}=0\end{array}$ \\
\hline High & $\begin{array}{c}\mu_{\text {mod }}=0 \\
\mu_{\text {good }}=0 \\
\mu_{\text {exc }}=1\end{array}$ & $\begin{array}{c}\mu_{\text {mod }}=0 \\
\mu_{\text {good }}=0 \\
\mu_{\text {exc }}=1\end{array}$ & $\begin{array}{l}\mu_{\text {mod }}=0 \\
\mu_{\text {good }}=\frac{1}{2} \\
\mu_{\text {exc }}=1 / 2\end{array}$ & $\begin{array}{c}\mu_{\mathrm{mod}}=0 \\
\mu_{\mathrm{good}}=0 \\
\mu_{\mathrm{exc}}=1\end{array}$ & $\begin{array}{l}\mu_{\text {mod }}=0 \\
\mu_{\text {good }}=\frac{1}{2} \\
\mu_{\text {exc }}=1 / 2\end{array}$ & $\begin{array}{c}\mu_{\text {mod }}=0 \\
\mu_{\text {good }}=1 \\
\mu_{\text {exc }}=0\end{array}$ & $\begin{array}{l}\mu_{\text {mod }}=0 \\
\mu_{\text {good }}=\frac{1}{2} \\
\mu_{\text {exc }}=1 / 2\end{array}$ & $\begin{array}{c}\mu_{\text {mod }}=0 \\
\mu_{\text {good }}=0 \\
\mu_{\text {exc }}=1\end{array}$ & $\begin{array}{c}\mu_{\text {mod }}=\frac{1}{2} \\
\mu_{\text {good }}=\frac{1}{2} \\
\mu_{\text {exc }}=0\end{array}$ \\
\hline
\end{tabular}


Table 13. Fuzzy membership values and probabilities.

\begin{tabular}{cccc}
\hline $\mathbf{p}\left(\widetilde{\mathbf{F}}_{\text {excellent }}\right)$ & $\mathbf{p}\left(\widetilde{\mathbf{F}}_{\text {good }}\right)$ & $\mathbf{p}\left(\widetilde{\mathbf{F}}_{\text {moderate }}\right)$ & $\sum_{\mathbf{m}=1}^{3} \mathbf{p}\left(\widetilde{\mathbf{F}}_{\mathbf{m}}\right)$ \\
\hline 0.3149 & 0.4444 & 0.2407 & 1 \\
\hline
\end{tabular}

A sum of 1 for the three fuzzy probabilities verifies that calculations are correct [18]. The fuzzy expected utility values are calculated based on Equation (12) and are presented in Table 14, together with the expected utilities from simple multicriteria approach. Scenario 9 is the preferred application in both cases.

Table 14. Simple and fuzzy Bayes' utility values.

\begin{tabular}{cccccccccc}
\hline Scenario $\rightarrow$ & $\mathbf{1}$ & $\mathbf{2}$ & $\mathbf{3}$ & $\mathbf{4}$ & $\mathbf{5}$ & $\mathbf{6}$ & $\mathbf{7}$ & $\mathbf{8}$ & $\mathbf{9}$ \\
\hline $\begin{array}{c}\text { Simple } \\
\text { multicriteria } \\
\boldsymbol{E}\left(\boldsymbol{a}_{\boldsymbol{j}}\right)\end{array}$ & 3.2420 & 3.2420 & 3.2420 & 3.6341 & 4.8799 & 4.9742 & 4.0259 & 5.6277 & 6.5173 \\
\hline Fuzzy $\boldsymbol{E}\left(\boldsymbol{a}_{\boldsymbol{j}}\right)$ & 3.0000 & 3.0000 & 3.0000 & 3.3627 & 4.5156 & 4.6029 & 3.7254 & 5.2077 & 6.0309 \\
\hline
\end{tabular}

Scenario 9 is the preferred scenario in both approaches. The ranking order is preserved in both cases. The distance, though, is denser among the fuzzy utilities group, showing that various irrigation scenarios are competing strongly with each other. Scenarios 5 and 6 still have high utility.

\subsection{Decision Tree and the ID3 Algorithm}

The logic presented in Section 2.7 along with the specific feature engineering selection [91] produced an exhaustive table of 486 rows (sample shown in Table 15) where the combinations of the above attributes are examined. In the table below, a sample of the training data is given. The entropy and information gain was calculated for each attribute in order to set the hierarchy and the splitting nodes of the decision tree. Figure 4 shows the decision tree obtained by ID3 algorithm for relative irrigation equal to $75 \%$ (Figure $4 a$ ) and $100 \%$ (Figure $4 \mathrm{~b}$ ) of the recommended. The results for $50 \%$ relative irrigation are omitted from Figure 4 as they only lead to low profit (L).

Table 15. Decision tree sample training data.

\begin{tabular}{ccccccccc}
\hline $\begin{array}{c}\text { Management } \\
\text { Practice }\end{array}$ & $\begin{array}{c}\text { Soil } \\
\text { Type }\end{array}$ & Climate & $\begin{array}{c}\text { Relative } \\
\text { Irrigation }\end{array}$ & $\begin{array}{c}\text { Trip } \\
\text { Reduction } \\
\text { Times }\end{array}$ & $\begin{array}{c}\text { Irrigation/ } \\
\text { Trip } \\
(\mathbf{m m} / \mathbf{h a})\end{array}$ & $\begin{array}{c}\text { Water } \\
\text { Price } \\
\left(\mathbf{\epsilon} / \mathbf{m}^{\mathbf{3}}\right)\end{array}$ & $\begin{array}{c}\text { Profit } \\
\mathbf{(} / \mathbf{h a})\end{array}$ & Profit \\
\hline M1 & Cl & Normal & $100 \%$ & 1 & 134.4 & 0.05 & 1480.1 & Medium \\
\hline M1 & SL & Wet & $50 \%$ & 2 & 129.6 & 0.05 & 281.8 & Low \\
\hline M1 & SL & Normal & $50 \%$ & 2 & 72 & 0.13 & 679.5 & Low \\
\hline M1 & SL & Dry & $50 \%$ & 0 & 43.2 & 0.13 & 579.5 & Low \\
\hline
\end{tabular}




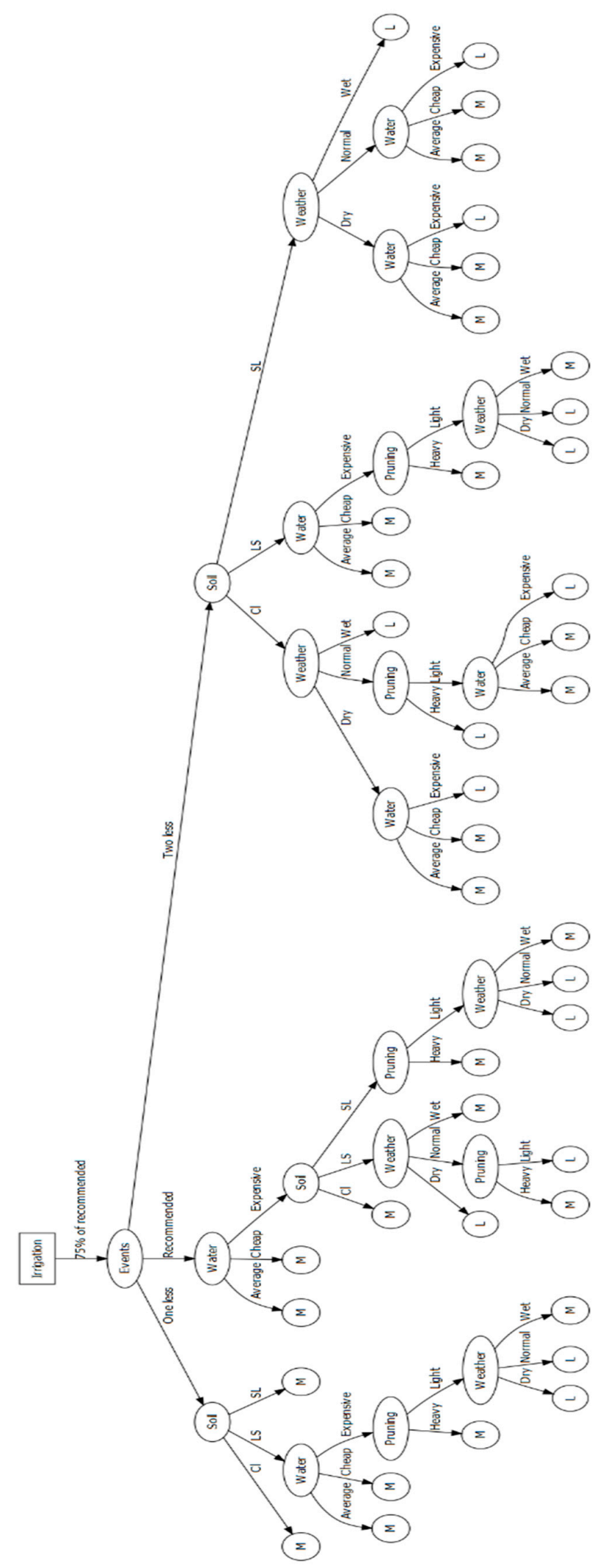

(a)

Figure 4. Cont. 


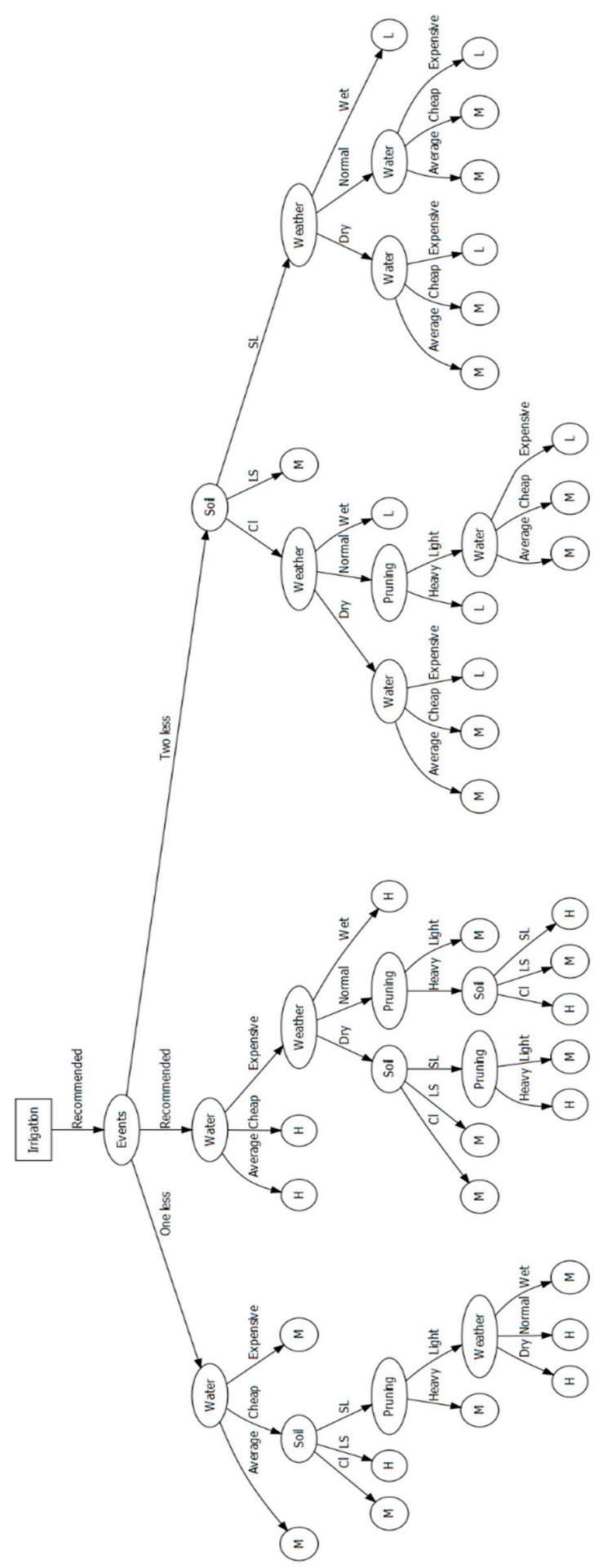

(b)

Figure 4. Decision tree using the ID3 algorithm for (a) 75\% of the recommended irrigation and (b) $100 \%$ of the recommended irrigation.

The Gini importance for each variable was estimated and normalized. The results are presented in Figure 5, ranked by overall importance. In the specific case study, irrigation-related decisions have the highest importance, with the amount of irrigation per event carrying $57.5 \%$ of the weight of the 
decision towards achieving a high profit. Water price, weather and soil texture follow with median values between $5.9 \%$ and $9.3 \%$, whereas pruning has a negligible effect on the decision.

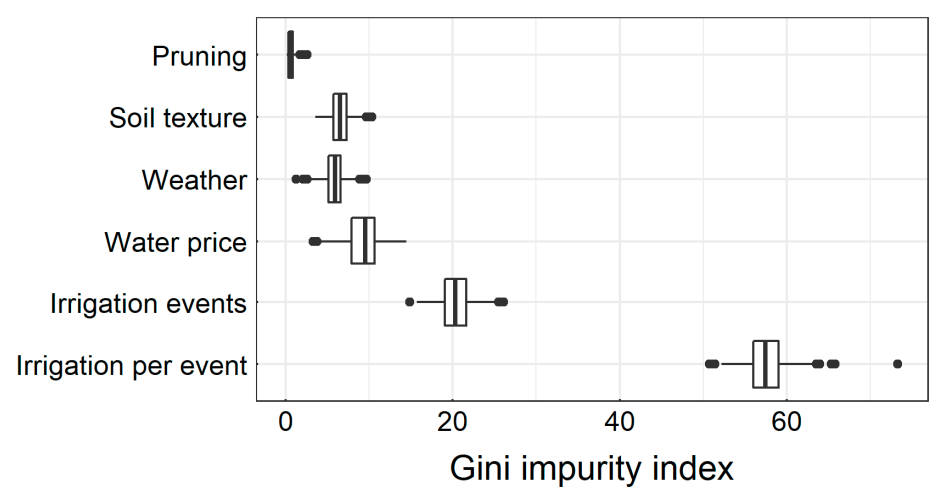

Figure 5. Gini index for the variables of the decision tree. Boxes depict the range of the $25-75 \%$ percentile of variable Gini's importance over all training iterations, and the bar is the median value. The whiskers depict the minimum and maximum values and the dots are outliers.

From the decision tree diagram, we obtain classifications for the route of actions we should follow when certain conditions occur. Those will determine the degree of profit we expect. The choice of profit rather than yield as the decision goal contributed to challenging the decision process because it is shaped by the cost and the revenue. An example of classification is: "During a wet year in a farm with clay soil type, we are going to have a low profit if we adopt a $75 \%$ relative irrigation and reduce the recommended number of irrigation events by 2." These decisions determine the degree of profit we expect given certain conditions.

If irrigation is kept at a low level (50\%), farm states or management subsequent decisions do not affect the final outcome which is always a low profit. In a sense, this can be considered as a "doing as little as possible, as much as necessary" approach in which the farmer refrains from investing effort and capital but also avoids any risk failing. This option can be especially attractive when there is lack of information (e.g., little knowledge of soil properties, crop behavior) or high uncertainty (e.g., market volatility, weather extremes). For example, one can irrigate at $75 \%$ per trip and still get low yield if the wrong management decisions are made. As irrigation volume per trip approaches the optimum $(75 \%$ and $100 \%$ ), alternatives become more complicated.

Sometimes, key factors will make no difference to the anticipated profit. For instance, we notice that in a $100 \%$ irrigation amount which is divided into the lowest number of trips, we never achieve a high profit no matter the soil type, precipitation or the management practice applied. Other factors, e.g., soil type and management practice, make a difference under specific climate conditions, e.g., a sandy loam farm with heavy pruning during a dry year will give a high profit.

An alternative reading of the decision tree is bottom-up, as the most relevant question is: "What irrigation strategy do I need to apply in order to achieve the best profit?" Thus, we would expect "relative irrigation" and "irrigation events reduction" to be the lower level nodes in the decision tree. But the case is that we placed "profit" as the classification column (Equation (17)) in decision for our training set of data. This means that the profit is the endpoint in our decision process, but it should be considered as an outcome rather than as an action we can take or apply to the problem. The reason the data were hierarchized like this is the means we had in order to produce them (the knowledge base reflected on Equation (3), the irrigation strategies modelling and cost-revenue estimations). In a reverse approach, we could have observed resulting profits from a known group of farms after a complete season and would have examined which attributes were applied in each and every case. All the parameters analyzed in Section 2.3 contribute to the calculations in order to formulate and give, as a result, the expected profit. That is why the decision tree resulted this way after processing the training data. We could have achieved a different structure of the tree if we had our training obtained in a 
different way. If we had statistical measurements of farms with known profit numbers and irrigation strategies, we could train the tree accordingly. Nevertheless, the takeaway after studying the tree nodes and paths is that we should not try to interpret it using a top-down approach. This can lead to paradox assumptions like, for instance, "How is it possible to begin examining if we should adopt a specific relative irrigation and yet we don't know during the process what is the soil type or the climate?" The trick is to deal with the classifications as combinations presented in the tree. This way, we will know how to act given conditions we cannot control like the weather or the soil type of our farm. What we can control, depending on the profit we want to achieve, are the irrigation schemes (amount and number of trips) and the management practices. It is apparent that the two major role players are the relative irrigation and the irrigation trips and that is why they are the top nodes.

To further analyze the decision tree shape, we owe to explain that throughout the training data set, the amount of irrigation as well as the number of trips were those proposed by the calculations as "optimal", given the parameters regarding weather and soil type each time. This means that we are examining a sort of "normalized" samples of irrigation schemes among the different soil types and weather conditions. This strengthens the importance of examining a path in the tree as coexistence of conditions in order to evaluate our decision options and define our course of action.

\subsection{Limitations}

The above method can be easily applied to other crops that have been parametrized for the FAO-56 equation. While FAO-56 is robust, it also has inherent limitations in the estimation of actual crop evapotranspiration [92]. Here, apart from the FAO-56 equation parameters, we can consider pruning, water price and yield price as decision parameters. In reality, there is a wide range of factors that can be accommodated by the model and have been used by other authors, e.g., nutrient pollution [93], topography, soil degradation and tree density [94], remote sensing information [95,96], tree hydration status [97], tree trunk diameter [98] pests [99], and socioeconomic parameters [100]. Moreover, under current assumptions and implementation, the decision tree shows obvious routes. When different prices of water and crop interact with each other, the decision tree will reach a point at which will not give such obvious paths anymore and there may be paths which lead to loss instead of profit. For example, under fixed extreme weather and water price scenarios, other variables may emerge as important or sensitive factors.

\section{Conclusions}

The probabilistic simple and fuzzy multicriteria approaches gave a ranking of the given irrigation strategies and displayed that a high utility can be found in scenarios which dictate low water consumption with fewer irrigation events while leading to higher crop yield and profit. Competing factors in fuzzy scoring (total profit versus the cost of irrigation water) were important for producing a more objective fuzzy engine. The probabilistic methods also displayed the shortcoming of not being able to exploit multiple features relevant to our case in the decision process. The decision tree approach showed that we can get a more refined proposal set when taking into consideration relevant factors like the weather and the soil type. This approach is recommended over the others presented and as it embraces a broader set of attributes that remain relevant to the decision and can provide tools which can receive higher adoption than traditional IDSS [17,32,33]. The methods and strategies examined are considered as more suitable for Mediterranean islands or across the globe, where water scarcity is a limiting factor.

Challenges to be investigated in future work include focusing on the production cost which depends heavily on water price. Under current and foreseen water stress conditions, an increase of agricultural water price is a very realistic and will certainly affect the profit, rendering the decision process an even more useful tool in the farming economy. Additionally, the price of olive oil in a selected region like the Mediterranean is adjusted each year and depends, among others, on the production levels. The decision system can point to wise decisions given the circumstances which can help farmers 
to survive a crisis. The importance of the correct decision will have a bigger impact then because the sustainability of the farming economy and water preservation with regard to environmental caution will be at a high stake.

Finally, we will analyze the behavior of a fuzzy ID3 implementation $[60,101]$ to obtain flexible thresholds to the attributes that change the path structure according to the degree of fuzziness applied.

Author Contributions: Conceptualization, M.M.; Methodology, P.C. and I.N.D.; Software, P.C.; Validation, I.N.D.; Formal Analysis, P.C. and I.N.D.; Writing-Original Draft Preparation, P.C. and I.N.D.; Writing-review \& editing, I.N.D. and M.M.; Visualization, P.C. and I.N.D.; Supervision, M.M. and T.M.; Funding acquisition, T.M. All authors have read and agreed to the published version of the manuscript.

Funding: This research has been co-financed by the European Union and Greek national funds through the Operational Program Competitiveness, Entrepreneurship and Innovation, under the call RESEARCH-CREATE—INNOVATE (Project Code: T1EDK-03372, DRip Irrigation Precise-DR.I.P: Development of an Advanced Precision Drip Irrigation System for Tree Crops coordinated by LANDCO Ltd.).

Acknowledgments: The authors acknowledge the contribution of ANELIXIS Consulting Development S.A. for providing grey literature on olive tree yield and water pricing in Crete. We give special thanks to the anonymous reviewers for their valuable comments, which improved this manuscript's quality.

Conflicts of Interest: The authors declare no conflict of interest.

\section{References}

1. Aquastat, FAO's Information System on Water and Agriculture, Food and Agriculture Organization (FAO) of the United Nation. Available online: http://www.fao.org/nr/water/aquastat (accessed on 5 December 2019).

2. Brauman, K.A.; Siebert, S.; Foley, J.A. Improvements in crop water productivity increase water sustainability and food security a global analysis. Environ. Res. Lett. 2013, 8, 24030. [CrossRef]

3. Cuevas, J.; Daliakopoulos, I.N.; del Moral, F.; Hueso, J.J.; Tsanis, I.K. A Review of Soil-Improving Cropping Systems for Soil Salinization. Agronomy 2019, 9, 295. [CrossRef]

4. Ali, M.H.; Talukder, M.S.U. Increasing water productivity in crop production-A synthesis. Agric. Water Manag. 2008, 95, 1201-1213. [CrossRef]

5. Fischer, G. Transforming the global food system. Nature 2018, 562, 501-502. [CrossRef]

6. WWAP. World Water Development Report Volume 4: Managing Water under Uncertainty and Risk; United Nations Educational, Scientific and cultural Organization: Paris, France, 2012; Volume 1.

7. Koutroulis, A.; Grillakis, M.; Daliakopoulos, I.; Tsanis, I.; Jacob, D. Cross sectoral impacts on water availability at $+2{ }^{\circ} \mathrm{C}$ and $+3{ }^{\circ} \mathrm{C}$ for east Mediterranean island states: The case of Crete. J. Hydrol. 2016, 532, 16-28. [CrossRef]

8. Giannakis, E.; Bruggeman, A.; Djuma, H.; Kozyra, J.; Hammer, J. Water pricing and irrigation across Europe: Opportunities and constraints for adopting irrigation scheduling decision support systems. Water Sci. Technol. Water Supply 2016, 16, 245-252. [CrossRef]

9. Labadie, J.W.; Sullivan, C.H. Computerized decision support systems for water managers. J. Water Resour. Plan. Manag. 1986, 112, 299-307. [CrossRef]

10. Gurría, A. Sustainably managing water: Challenges and responses. Water Int. 2009, 34, 396-401. [CrossRef]

11. Paredes, P.; Wei, Z.; Liu, Y.; Xu, D.; Xin, Y.; Zhang, B.; Pereira, L.S. Performance assessment of the FAO AquaCrop model for soil water, soil evaporation, biomass and yield of soybeans in North China Plain. Agric. Water Manag. 2015, 152, 57-71. [CrossRef]

12. Steduto, P.; Hsiao, T.C.; Raes, D.; Fereres, E. AquaCrop-The FAO Crop Model to Simulate Yield Response to Water: I. Concepts and Underlying Principles. Agron. J. 2009, 101, 426-437. [CrossRef]

13. Foster, T.; Brozović, N.; Butler, A.P.; Neale, C.M.U.; Raes, D.; Steduto, P.; Fereres, E.; Hsiao, T.C. AquaCrop-OS: An open source version of FAO's crop water productivity model. Agric. Water Manag. 2017, 181, 18-22. [CrossRef]

14. Mannini, P.; Genovesi, R.; Letterio, T. IRRINET: Large Scale DSS Application for On-farm Irrigation Scheduling. Procedia Environ. Sci. 2013, 19, 823-829. [CrossRef]

15. Allen, R.G.; Pereira, L.S.; Raes, D.; Smith, M. Others Crop Evapotranspiration-Guidelines for Computing Crop Water Requirements-FAO Irrigation and Drainage Paper 56; FAO: Rome, Italy, 1998; Volume 300, p. 6541. 
16. Rinaldi, M.; He, Z. Decision Support Systems to Manage Irrigation in Agriculture. In Advances in Agronomy; Academic Press Inc.: Cambridge, MA, USA, 2014; Volume 123, pp. 229-279.

17. Car, N.J. USING decision models to enable better irrigation Decision Support Systems. Comput. Electron. Agric. 2018, 152, 290-301. [CrossRef]

18. Kahraman, C.; Kabak, Ö. Fuzzy statistical decision-making. In Studies in Fuzziness and Soft Computing; Springer: Cham, Sweitzerland, 2016; p. 343.

19. Zimmermann, H.-J. Fuzzy Set Theory—And Its Applications; Springer: Dordrecht, Germany, 2001.

20. Chernov, V.; Dorokhov, O.; Dorokhova, L.; Chubuk, V. Using fuzzy logic for solution of economic tasks: Two examples of decision making under uncertainty 85. ELIT-Econ. Lab. Transit. Res. 2013, 9, 85-100.

21. Bates, J.H.T.; Young, M.P. Applying fuzzy logic to medical decision making in the intensive care unit. Am. J. Respir. Crit. Care Med. 2003, 167, 948-952. [CrossRef] [PubMed]

22. Yao, J.F.F.; Yao, J.S. Fuzzy decision making for medical diagnosis based on fuzzy number and compositional rule of inference. Fuzzy Sets Syst. 2001, 120, 351-366. [CrossRef]

23. Ross, T.J. Fuzzy Logic with Engineering Applications, 3rd ed.; Wiley: West Sussex, UK, 2010; p. 580.

24. Christias, P. A comparative study on decision support approaches under uncertainty. In Business Information Systems Workshops; Abramowicz, W., Paschke, A., Eds.; BIS 2018. Lecture Notes in Business Information Processing; Springer: Cham, Switzerland, 2019; Volume 339, pp. 517-526.

25. Bellman, R.E.; Zadeh, L.A. Decision-Making in a Fuzzy Environment. Manag. Sci. 1970, 17, $141-164$. [CrossRef]

26. Baghban, A.; Jalali, A.; Shafiee, M.; Ahmadi, M.H.; Chau, K. Developing an ANFIS-based swarm concept model for estimating the relative viscosity of nanofluids. Eng. Appl. Comput. Fluid Mech. 2019, 13, 26-39. [CrossRef]

27. Shamshirband, S.; Rabczuk, T.; Chau, K.W. A Survey of Deep Learning Techniques: Application in Wind and Solar Energy Resources. IEEE Access 2019, 7, 164650-164666. [CrossRef]

28. Najafi, B.; Faizollahzadeh Ardabili, S.; Shamshirband, S.; Chau, K.; Rabczuk, T. Application of ANNs, ANFIS and RSM to estimating and optimizing the parameters that affect the yield and cost of biodiesel production. Eng. Appl. Comput. Fluid Mech. 2018, 12, 611-624. [CrossRef]

29. Ardabili, S.F.; Najafi, B.; Shamshirband, S.; Bidgoli, B.M.; Deo, R.C.; Chau, K.W. Computational intelligence approach formodeling hydrogen production: A review. Eng. Appl. Comput. Fluid Mech. 2018, 12, 438-458.

30. Wang, W.C.; Xu, L.; Chau, K.W.; Xu, D. Yin-Yang firefly algorithm based on dimensionally Cauchy mutation. Expert Syst. Appl. 2020, 150, 113216. [CrossRef]

31. Fotovatikhah, F.; Herrera, M.; Shamshirband, S.; Chau, K.W.; Ardabili, S.F.; Piran, M.J. Survey of computational intelligence as basis to big flood management: Challenges, research directions and future work. Eng. Appl. Comput. Fluid Mech. 2018, 12, 411-437. [CrossRef]

32. Giusti, E.; Marsili-Libelli, S. A Fuzzy Decision Support System for irrigation and water conservation in agriculture. Environ. Model. Softw. 2015, 63, 73-86. [CrossRef]

33. Li, M.; Sui, R.; Meng, Y.; Yan, H. A real-time fuzzy decision support system for alfalfa irrigation. Comput. Electron. Agric. 2019, 163, 104870. [CrossRef]

34. Tsanis, I.K.; Koutroulis, A.G.; Daliakopoulos, I.N.; Jacob, D. Severe climate-induced water shortage and extremes in Crete. Clim. Chang. 2011, 106, 667-677. [CrossRef]

35. Daliakopoulos, I.N.; Panagea, I.S.; Tsanis, I.K.; Grillakis, M.G.; Koutroulis, A.G.; Hessel, R.; Mayor, A.G.; Ritsema, C.J. Yield Response of Mediterranean Rangelands under a Changing Climate. Land Degrad. Dev. 2017, 28, 1962-1972. [CrossRef]

36. Er-Raki, S.; Chehbouni, A.; Hoedjes, J.; Ezzahar, J.; Duchemin, B.; Jacob, F. Improvement of FAO-56 method for olive orchards through sequential assimilation of thermal infrared-based estimates of ET. Agric. Water Manag. 2008, 95, 309-321. [CrossRef]

37. Allen, R.G.; Pruitt, W.O.; Wright, J.L.; Howell, T.A.; Ventura, F.; Snyder, R.; Itenfisu, D.; Steduto, P.; Berengena, J.; Yrisarry, J.B.; et al. A recommendation on standardized surface resistance for hourly calculation of reference ETo by the FAO56 Penman-Monteith method. Agric. Water Manag. 2006, 81, 1-22. [CrossRef]

38. Blaney, H.F.; Criddle, W.D. Determining Consumptive Use and Irrigation Water Requirements; US Department of Agriculture: Washington, DC, USA, 1962. 
39. Kuslu, Y.; Sahin, U.; Tunc, T.; Kiziloglu, F.M. Determining water-yield relationship, water use efficiency, seasonal crop and pan coefficients for alfalfa in a semiarid region with high altitude. Bulg. J. Agric. Sci. 2010, $16,482-492$.

40. Istanbulluoglu, A. Effects of irrigation regimes on yield and water productivity of safflower (Carthamus tinctorius L.) under Mediterranean climatic conditions. Agric. Water Manag. 2009, 96, 1792-1798. [CrossRef]

41. Kipkorir, E.; Raes, D.; Massawe, B. Seasonal water production functions and yield response factors for maize and onion in Perkerra, Kenya. Agric. Water Manag. 2002, 56, 229-240. [CrossRef]

42. Akhter, J.; Mahmood, K.; Tasneem, M.A.; Naqvi, M.H.; Malik, K.A. Comparative water-use efficiency of Sporobolus arabicus and Leptochloa fusca and its relation with carbon-isotope discrimination under semi-arid conditions. Plant Soil 2003, 249, 263-269. [CrossRef]

43. Lovelli, S.; Perniola, M.; Ferrara, A.; Di Tommaso, T. Yield response factor to water (Ky) and water use efficiency of Carthamus tinctorius L. and Solanum melongena L. Agric. Water Manag. 2007, 92, 73-80. [CrossRef]

44. Steduto, P.; Hsiao, T.C.; Fereres, E.; Raes, D. Crop Yield Response to Water; FAO: Rome, Italy, 2012.

45. Moutonnet, P. Yield response factors of field crops to deficit irrigation. In Deficit Irrigation Practices. Water Reports 22; FAO: Rome, Italy, 2002; pp. 11-15.

46. Popova, Z.; Eneva, S.; Pereira, L.S. Model Validation, Crop Coefficients and Yield Response Factors for Maize Irrigation Scheduling based on Long-term Experiments. Biosyst. Eng. 2006, 95, 139-149. [CrossRef]

47. Orgaz, F.; Fereres, E. Riego. El Cultivo del Olivo; Barranco, D., Fernandez-Escobar, R., Rallo, L., Eds.; Ediciones Mundi-Prensa: Madrid, Spain, 2017; pp. 251-272.

48. Allen, R.G.; Pereira, L.S. Estimating crop coefficients from fraction of ground cover and height. Irrig. Sci. 2009, 28, 17-34. [CrossRef]

49. Rai, R.K.; Singh, V.P.; Upadhyay, A. Planning and Evaluation of Irrigation Projects: Methods and Implementation; Elsevier: Amsterdam, The Netherlands, 2017.

50. Allen, R.G. Using the FAO-56 dual crop coefficient method over an irrigated region as part of an evapotranspiration intercomparison study. J. Hydrol. 2000, 229, 27-41. [CrossRef]

51. Torres-Ruíz, J.M.; Fernández, J.E.; Girón, I.F.; Romero, R.; Jiménez-Bocanegra, J.A.; García Tejero, I.; Martín-Palomo, M.J. Determining evapotranspiration in an olive orchard in Southwest Spain. Acta Hortic. 2012, 949, 251-258. [CrossRef]

52. Fereres, E.; Villalobos, F.J.; Orgaz, F.; Testi, L. Water requirements and irrigation scheduling in olive. Acta Hortic. 2011, 888, 31-40. [CrossRef]

53. Stuart, M.; Ross, S.M. Introduction to Probability and Statistics for Engineers and Scientists. J. R. Stat. Soc. Ser. A 1988, 151, 381. [CrossRef]

54. Pownuk, A.; Kreinovich, V. Decision making under uncertainty. In Combining Interval, Probabilistic, and Other Types of Uncertainty in Engineering Applications. Studies in Computational Intelligence; Springer: Cham, Switzerland, 2018; Volume 773, pp. 157-190.

55. Pirie, W.R.; Freund, J.E. Introduction to Probability. J. Am. Stat. Assoc. 1973, 68, 1028. [CrossRef]

56. Bertsekas, D.P.; Tsitsiklis, J.N. Introduction to Probability, 2nd ed.; Athena Scientific: Nashua, NH, USA, 2008; Volume 1, pp. 18-43.

57. Christias, P.; Mocanu, M. Enhancing bayes' probabilistic decision support with a fuzzy approach. In Proceedings of the 2019 22nd International Conference on Control Systems and Computer Science, CSCS 2019, Bucharest, Romania, 28-30 May 2019.

58. Alsolami, F.; Azad, M.; Chikalov, I.; Moshkov, M. Decision and Inhibitory Trees and Rules for Decision Tables with Many-Valued Decisions; Springer Nature Switzerland AG: Cham, Switzerland, 2020; Volume 156, pp. 17-36, 91-103.

59. Hssina, B.; Merbouha, A.; Ezzikouri, H.; Erritali, M. A comparative study of decision tree ID3 and C4.5. Int. J. Adv. Comput. Sci. Appl. 2014, 4, 13-19. [CrossRef]

60. Machine Learning: Complete Beginners Guide for Neural Networks, Algorithms, Random Forests and Decision Tress Made Simple; CreateSpace Independent Publishing: Scotts Valley, CA, USA, 2017.

61. Altay, A.; Cinar, D. Fuzzy decision trees. Stud. Fuzziness Soft Comput. 2016, 343, 221-261.

62. Di Prima, S.; Castellini, M.; Pirastru, M.; Keesstra, S. Soil Water Conservation: Dynamics and Impact. Water 2018, 10, 952. [CrossRef]

63. Akkaş, E.; Akin, L.; Evren Çubukçu, H.; Artuner, H. Application of Decision Tree Algorithm for classification and identification of natural minerals using SEM-EDS. Comput. Geosci. 2015, 80, 38-48. [CrossRef] 
64. Wang, Y.Y.; Li, Y.B.; Rong, X.W. Improvement of ID3 algorithm based on simplified information entropy and coordination degree. In Proceedings of the Chinese Automation Congress, (CAC), IEEE, Jinan, China, 20-22 October 2017; pp. 1526-1550.

65. Breiman, L. Technical Note: Some Properties of Splitting Criteria. Mach. Learn. 1996, 24, 41-47. [CrossRef]

66. Cano, G.; Garcia-Rodriguez, J.; Garcia-Garcia, A.; Perez-Sanchez, H.; Benediktsson, J.A.; Thapa, A.; Barr, A. Automatic selection of molecular descriptors using random forest: Application to drug discovery. Expert Syst. Appl. 2017, 72, 151-159. [CrossRef]

67. Friedman, J.; Hastie, T.; Tibshirani, R. The Elements of Statistical Learning: Data Mining, Inference, and Prediction, 2nd ed.; Springer: Cham, Switzerland, 2016.

68. Bluemke, I.; Stepień, A. Selection of Metrics for the Defect Prediction; Springer: Cham, Switzerland, 2016; pp. 39-50.

69. Koutroulis, A.G.; Vrohidou, A.-E.K.; Tsanis, I.K. Spatiotemporal Characteristics of Meteorological Drought for the Island of Crete. J. Hydrometeorol. 2011, 12, 206-226. [CrossRef]

70. Tsanis, I.; Naoum, S. The effect of spatially distributed meteorological parameters on irrigation water demand assessment. Adv. Water Resour. 2003, 26, 311-324. [CrossRef]

71. Naoum, S.; Tsanis, I.K. Temporal and spatial variation of annual rainfall on the island of Crete, Greece. Hydrol. Process. 2003, 17, 1899-1922. [CrossRef]

72. Hellenic Statistical Authority. Annual Agricultural Statistics Report of the Hellenic Statistical Authority (ELSTAT). 2008. Available online: https://www.statistics.gr/en/hellenic_statistical_programme (accessed on 5 December 2019).

73. Petousi, I.; Daliakopoulos, I.N.; Matsoukas, T.; Zotos, N.; Mavrogiannis, I.; Manios, T. DRIP: Development of an Advanced Precision Drip Irrigation System for Tree Crops. Terraenvision Abstr. 2018, 1, 2018-2022.

74. Chartzoulakis, K.S. The use of saline water for irrigation of olives: Effects on growth, physiology, yield and oil quality. Acta Hortic. 2011, 888, 97-108. [CrossRef]

75. Phogat, V.; Skewes, M.A.; Cox, J.W.; Sanderson, G.; Alam, J.; Šimůnek, J. Seasonal simulation of water, salinity and nitrate dynamics under drip irrigated mandarin (Citrus reticulata) and assessing management options for drainage and nitrate leaching. J. Hydrol. 2014, 513, 504-516. [CrossRef]

76. Egea, G.; Diaz-Espejo, A.; Fernández, J.E. Soil moisture dynamics in a hedgerow olive orchard under well-watered and deficit irrigation regimes: Assessment, prediction and scenario analysis. Agric. Water Manag. 2016, 164, 197-211. [CrossRef]

77. Agricultural News. Agricultural Input for Olive Trees and Olive Oil. 2019. Available online: https: //www.news247.gr/agrotika/oi-eisroes-stin-elia-kai-to-elaiolado.6634173.html (accessed on 5 December 2019).

78. OECD. Environmental Performance Reviews: Greece 2009; OECD Publications: Paris, France, 2009.

79. Kapsalis, P.C.; Kritsotaki, M.A. 1st Revision of the River Basin Management Plan of the River Basin Districts of Crete (EL 13) Draft River Basin Management Plan, 3rd ed.; Hellenic Ministry of Environment and Energy: Athens, Greece, 2017.

80. Stefanoudaki, E.; Chartzoulakis, K.; Koutsaftakis, A.; Kotsifaki, F. Effect of drought stress on qualitative characteristics of olive oil of cv Koroneiki. Grasas Aceites 2001, 52, 202-206. [CrossRef]

81. Chartzoulakis, K.; Michelakis, N.; Tzompanakis, I. Effects of water amount and application date on yield and water utilization efficiency of "Koroneiki" olives under drip irrigation. Adv. Hortic. Sci. 1992, 6, 82-84.

82. POOLred-Origin Price Information System for the Olive Oil Counting Market. Available online: http: //www.poolred.com/ (accessed on 5 December 2019).

83. Hellenic Ministry of Agriculture (HMU). Modernization of the Methodology of Calculating Irrigation Requirements Used in the Agricultural Technical Studies of Land Reclamation Projects and Adaptation to the Greek Conditions. Hellenic Ministry of Agriculture, Decision 120.344 11/2/1992. 1992. Available online: http://goodagro.org/docs/1992_Apofasi_Penman.pdf (accessed on 5 December 2019).

84. Saxton, K.E.; Rawls, W.J. Soil Water Characteristic Estimates by Texture and Organic Matter for Hydrologic Solutions. Soil Sci. Soc. Am. J. 2006, 70, 1569-1578. [CrossRef]

85. Gul, F.; Pesendorfer, W. Expected Uncertain Utility Theory. Econometrica 2014, 82, 1-39. [CrossRef]

86. Fishburn, P.C. Utility Theory and Decision Theory. In Utility and Probability; Palgrave Macmillan: London, UK, 1990; pp. 303-312. 
87. Sadollah, A. Introductory Chapter: Which Membership Function is Appropriate in Fuzzy System? In Fuzzy Logic Based in Optimization Methods and Control Systems and its Applications; InTechOpen: London, UK, 2018. [CrossRef]

88. Mcneil, B.; Pauker, S.G. Decision Analysis for Public Health: Principles and Illustrations. Ann. Rev. Public Health 1984, 5, 135-161. [CrossRef]

89. Gravel, N.; Marchant, T.; Sen, A. Conditional expected utility criteria for decision making under ignorance or objective ambiguity. J. Math. Econ. 2018, 78, 79-95. [CrossRef]

90. Luce, R.D.; Krantz, D.H. Conditional Expected Utility. Econometrica 1971, 39, 253. [CrossRef]

91. Sheppard, C. Tree-Based Machine Learning Algorithms: Decision Trees, Random Forests, and Boosting; CreateSpace Independent Publishing Platform: Scotts Valley, CA, USA, 2017; p. 110.

92. Subedi, A.; Chávez, J.L. Crop Evapotranspiration (ET) Estimation Models: A Review and Discussion of the Applicability and Limitations of ET Methods. J. Agric. Sci. 2015, 7, 50. [CrossRef]

93. Li, M.; Guo, P.; Liu, X.; Huang, G.; Huo, Z. A decision-support system for cropland irrigation water management and agricultural non-point sources pollution control. Desalin. Water Treat. 2014, 52, 5106-5117. [CrossRef]

94. Delgado, G.; Aranda, V.; Calero, J.; Sánchez-Marañón, M.; Serrano, J.M.; Sánchez, D.; Vila, M.A. Building a Fuzzy Logic Information Network and a Decision-Support System for Olive Cultivation in Andalusia [Spain]. Span. J. Agric. Res. 2008, 6, 252-263. [CrossRef]

95. Katsigiannis, P.; Galanis, G.; Dimitrakos, A.; Tsakiridis, N.; Kalopesas, C.; Alexandridis, T.; Chouzouri, A.; Patakas, A.; Zalidis, G. Fusion of spatio-temporal UAV and proximal sensing data for an agricultural decision support system. In Proceedings of the Fourth International Conference on Remote Sensing and Geoinformation of the Environment (RSCy2016), Paphos, Cyprus, 12 August 2016; Volume 9688, p. 96881R.

96. Daliakopoulos, I.N.; Grillakis, E.G.; Koutroulis, A.G.; Tsanis, I.K. Tree crown detection on multispectral VHR satellite imagery. Photogramm. Eng. Remote Sens. 2009, 75, 1201-1212. [CrossRef]

97. Torres, I.; Sánchez, M.T.; Benlloch-González, M.; Pérez-Marín, D. Irrigation decision support based on leaf relative water content determination in olive grove using near infrared spectroscopy. Biosyst. Eng. 2019, 180, 50-58. [CrossRef]

98. Moriana, A.; Girón, I.F.; Martín-Palomo, M.J.; Conejero, W.; Ortuño, M.F.; Torrecillas, A.; Moreno, F. New approach for olive trees irrigation scheduling using trunk diameter sensors. Agric. Water Manag. 2010, 97, 1822-1828. [CrossRef]

99. Zaza, C.; Bimonte, S.; Faccilongo, N.; La Sala, P.; Contò, F.; Gallo, C. A new decision-support system for the historical analysis of integrated pest management activities on olive crops based on climatic data. Comput. Electron. Agric. 2018, 148, 237-249. [CrossRef]

100. Carmona-Torres, C.; Parra-López, C.; Hinojosa-Rodríguez, A.; Sayadi, S. Farm-level multifunctionality associated with farming techniques in olive growing: An integrated modeling approach. Agric. Syst. 2014, 127, 97-114. [CrossRef]

101. Liang, G. A Comparative Study of three Decision Tree Algorithms: ID3, Fuzzy ID3 and Probabilistic Fuzzy ID3; Erasmus University: Rotterdam, The Netherlands, 2005.

(C) 2020 by the authors. Licensee MDPI, Basel, Switzerland. This article is an open access article distributed under the terms and conditions of the Creative Commons Attribution (CC BY) license (http://creativecommons.org/licenses/by/4.0/). 